\title{
A STUDY ON SIX MINUTE WALK TEST AMONG CHRONIC OBSTRUCTIVE PULMONARY DISEASE PATIENTS
}

\author{
T. Dhanasekar1, Irfan Ismail Ayub², Pavithra M³, Sindhura Koganti ${ }^{4}$, Koushik Muthu Raja ${ }^{5}$, Abdul Majeed Arshad 6 , B. Rajagopalan ${ }^{7}$
}

${ }^{1}$ Associate Professor, Department of Pulmonary Medicine, Sri Ramachandra Medical College \& Research Institute, Sri Ramachandra University.

${ }^{2}$ Assistant Professor, Department of Pulmonary Medicine, Sri Ramachandra Medical College \& Research Institute, Sri Ramachandra University.

${ }^{3}$ Respiratory Technologist, Department of Pulmonary Medicine, Sri Ramachandra Medical College \& Research Institute,

Sri Ramachandra University.

${ }_{4}^{4}$ Assistant Professor, Department of Pulmonary Medicine, Sri Ramachandra Medical College \& Research Institute,

Sri Ramachandra University.

${ }^{5}$ Assistant Professor, Department of Pulmonary Medicine, Sri Ramachandra Medical College \& Research Institute,

Sri Ramachandra University.

${ }^{6}$ Assistant Professor, Department of Pulmonary Medicine, Sri Ramachandra Medical College \& Research Institute,

Sri Ramachandra University.

7Professor \& HOD, Department of Pulmonary Medicine, Sri Ramachandra Medical College \& Research Institute,

Sri Ramachandra University.

\section{ABSTRACT}

\section{BACKGROUND}

Chronic Obstructive Pulmonary Disease (COPD) is characterized by airflow obstruction that is usually progressive and may be accompanied by airway hypersensitivity and be partially reversible (Ref. 1). Recent advances have led researchers to look at patients with COPD beyond just spirometric classification and identify other systemic manifestations of the disease that may contribute to morbidity and mortality. The Six Minute Walk Test (6MWT) is a practical and simple test. This test measures the distance that a patient can quickly walk on a flat, hard surface in a period of six minutes. It evaluates the global and integrated responses of all the systems involved during exercise including the pulmonary and cardiovascular systems, systemic circulation, peripheral circulation, blood and neuromuscular units. Hence, the six minute walk distance may better reflect the functional exercise level for daily physical activities. Our aim of the study was to correlate the severity of Chronic Obstructive Pulmonary Disease patients (COPD) with Six Minute Walk Test (6MWT).

\section{KEYWORDS}

I-GEL, Classical LMA, Intraocular Pressure, Endotracheal Tube, Haemodynamic Response.

HOW TO CITE THIS ARTICLE: Dhanasekar T, Ayub II, Pavithra M, et al. A study on six minute walk test among chronic obstructive pulmonary disease patients. J. Evolution Med. Dent. Sci. 2016;5(41):2520-2523, DOI: 10.14260/jemds/2016/588

\section{INTRODUCTION}

Chronic Obstructive Pulmonary Disease (COPD) is characterized by airflow obstruction that is usually progressive and may be accompanied by airway hypersensitivity and be partially reversible. ${ }^{1}$ Chronic Obstructive Pulmonary Disease is a major cause of morbidity and mortality throughout the world. It is currently the $4^{\text {th }}$ leading cause of death in the world. The death rate from the disease has increased in recent decades in apparent association with an increase in cigarette smoking and air pollution.2-3

COPD is primarily a disease of the adult. The reported prevalence of COPD varies according to different populationbased studies from India. The prevalence rates in males varies from $2.1 \%$ to $9.4 \%$ and $1.4 \%$ to $4.08 \%$ in patients from North and South India respectively. In females, it varies from $1.33 \%$ to $4.9 \%$ and $2.55 \%$ to $2.7 \%$ from North and South India respectively.

Financial or Other, Competing Interest: None.

Submission 28-04-2016, Peer Review 05-05-2016,

Acceptance 07-05-2016, Published 21-05-2016.

Corresponding Author:

Dr. T. Dhanasekar,

A J 147, No. 3,

Golden Astar Apartments,

$9^{\text {th }}$ Main Road, Anna Nagar,

Chennai-600040.

E-mail: drdhansekar@yahoo.com

DOI: $10.14260 /$ jemds/2016/588
The rounded-off median prevalence rates were assessed as $5 \%$ for male and $2.7 \%$ for female subjects of over 30 years of age. The disease is distinctly more common in males. The male-to-female ratio varied from 1.32:1 to $2.6: 1$ in different studies with a median ratio of 1.6: 1.

Recent studies have looked at COPD as not just a pulmonary disorder, but a systemic disease that has systemic effects that can contribute substantially to its morbidity and mortality. Weight loss, muscle weakness and osteoporosis are among a variety of common features of advanced COPD, each of which contributes to the symptoms, morbidity and probably the mortality of COPD. The mechanism of these systemic effects are poorly understood, but may be related to persistent airway inflammation and elevated level of circulating inflammatory mediators. Spirometry alone provides little or no inflammation about the extrapulmonary effect of COPD.

The self-paced six minute walk assesses the submaximal level of functional capacity. ${ }^{4-6}$ Most patients do not achieve maximal exercise capacity during the 6MWT. Instead, they choose their own intensity of exercise and are allowed to stop and rest during the test. However, because most activities of daily living performed are submaximal levels of exertion, the six minute walk distance may better reflect the functional exercise level for daily physical activities. ${ }^{7}$

The 6MWT is safe, easier to administer, better tolerated and better reflects activities of daily living than other walk test (Such as shuttle walk test). 


\section{MATERIALS AND METHODS}

This study was done on all patients with COPD attending the Chest OPD at Sri Ramachandra Medical Centre and Hospital of Sri Ramachandra University between November 2006 and March 2007.

\section{Inclusion Criteria}

- Patients belonging to the age group of 20-75 years.

- Smokers or ex-smokers.

- $\quad$ Patients who were able to perform pulmonary function testing.

\section{Exclusion Criteria}

- Patient with chest pain.

- Patient with cardiac problems.

- Patients with resting heart rate of more than $120 \mathrm{~b} / \mathrm{min}$.

- Patient with systolic blood pressure of more than 180 mmHg.

- $\quad$ Patient with reversible airway disease.

Patients who met the inclusion criteria were included in the study. A detailed history was obtained and recorded from these patients. Details recorded included personal particulars, presence and duration of symptoms (Cough, expectoration, wheeze, dyspnoea, chest pain). A detailed clinical examination was also performed.

A Pulmonary Function Test was done using KoKo spirometer (Medgraphics) to differentiate these patients into mild, moderate and severe COPD as per GOLD classification. ${ }^{8}$ as shown in Table 1.

\begin{tabular}{|c|c|}
\hline Severity & Measurements \\
\hline \multirow{3}{*}{ Mild } & FEV1/FVC $<70 \%$ \\
& PREDICTED \\
& FEV1 $>80 \%$ \\
\hline \multirow{3}{*}{ Moderate } & FEV1/FVC $<70 \%$ \\
& PREDICTED \\
& $30 \%<$ FEV $1<80 \%$ \\
\hline \multirow{2}{*}{ Severe } & FEV1/FVC $<70 \%$ \\
& PREDICTED \\
\hline \multicolumn{2}{|c|}{ Table 1: Gold Standards for COPD } \\
\hline
\end{tabular}

Prior to procedure, patient was explained about the procedure and informed consent was taken from the patient. Before starting of test, patients were made to sit in a chair for at least 10 minutes and blood pressure, heart rate, respiratory rate, oxygen saturation, dyspnoea and fatigue level was recorded. After briefing the procedure to the patient 6MWT was initiated for the patient.

Six Minute Walk Test was performed as per Guidelines of American Thoracic Society (ATS). The test was performed indoors, along a long flat straight corridor with a hard, nonslippery surface. The length of the corridor was $40 \mathrm{~m}$. Each one meter was marked in the floor using red Tape (Fig. no. 2).

The patient was asked to start walking and the stopwatch was started. Patient was instructed not to talk while walking and symptoms of fatigue or discomfort were noted. Patients were encouraged to walk as fast as possible. Test was stopped exactly at the end of six minutes. If the patient was unable to complete the six minutes, then the reason for stopping was noted.
The following variables of the 6MWT were recorded at the end of the test: 1) Distance walked, 2) Duration, 3) Heart rate at the start and finish of the test, 4) Subjective dyspnoea grading by Borg's scale at the start and end of the test, 5) Oxygen saturation by finger pulse oximetry at the start and finish of the test, 6) Respiratory rate at the start and end of the test.

All Data's entries and analysis by using SPSS 8.0 Windows software and accordingly percentages and $\mathrm{P}$ value were calculated. $\mathrm{P}$ value was considered significant. Paired ' $\mathrm{T}$ ' test was done to find the statistical significance.

\section{RESULTS}

A total of 25 patients were recruited into the study. As per the GOLD severity classification of COPD mentioned above, the study group was majorly comprised of patients with severe COPD (14 patients) and is shown in Figure 1.

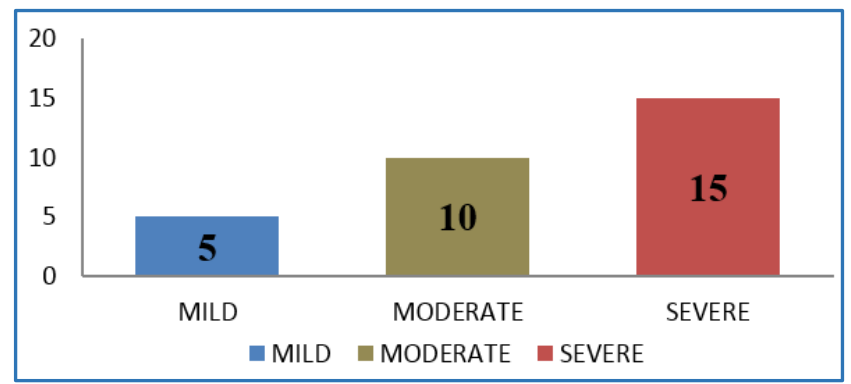

Fig. 1: Classification of COPD by Pulmonary Function Testing (Gold Guidelines)

Further age wise classification of the patients was done and is shown in Figure 2. The majority of our study group was in the 60-70 years' age group (40\%). Also, Figure 3 shows the distribution of the weight of the patients in our study group.

\begin{tabular}{|c|c|c|}
\hline Age & Number & Percentage \\
\hline $20-30$ & 2 & $8 \%$ \\
\hline $30-40$ & 2 & $8 \%$ \\
\hline $40-50$ & 0 & 0 \\
\hline $50-60$ & 8 & $32 \%$ \\
\hline $60-70$ & 10 & $40 \%$ \\
\hline 70 \& Above & 3 & $12 \%$ \\
\hline Total & 25 & $100 \%$ \\
\hline \multicolumn{3}{|c|}{ Fig. 2: Age Wise Distribution of COPD Patients } \\
\hline
\end{tabular}

\begin{tabular}{|c|c|c|}
\hline Weight & Number & Percentage \\
\hline $30-40$ & 1 & $4 \%$ \\
\hline $40-50$ & 8 & $32 \%$ \\
\hline $50-60$ & 11 & $44 \%$ \\
\hline $60-70$ & 5 & $20 \%$ \\
\hline Total & $\mathbf{2 5}$ & $\mathbf{1 0 0 \%}$ \\
\hline \multicolumn{2}{|c|}{ Fig. 3: Weight Wise Distribution of COPD Patients } \\
\hline
\end{tabular}

All the 25 patients were then encouraged to perform the 6MWT. Though all patients were encouraged to complete the full 6 minutes of the test, some patients were not able to complete the test in its entire duration. In the mild COPD group, out of a total of 4 patients 3 patients completed and 1 
did not complete within 6 minutes. In the moderate COPD group, of a total of 7 patients 6 patients completed and 1 did not complete the test. In the severe COPD group consisting of 14 patients, 8 patients completed the test and 1 did not complete within 6 minutes. The results of various parameters during the 6MWT are shown in Figures 4, 5 and 6.

\begin{tabular}{|c|c|c|c|c|c|}
\hline \multicolumn{2}{|c|}{ Variable } & $\begin{array}{l}\text { Pre } 6 \\
\text { MWT }\end{array}$ & $\begin{array}{l}\text { Post } 6 \\
\text { MWT }\end{array}$ & $\begin{array}{c}\mathbf{T} \\
\text { value }\end{array}$ & $\begin{array}{c}P \\
\text { value }\end{array}$ \\
\hline SPO2 & $\begin{array}{c}\text { Mean } \\
\text { S.D }\end{array}$ & $\begin{array}{c}96.8 \\
0.9\end{array}$ & $\begin{array}{l}96 \\
1.4\end{array}$ & 0.39 & $<0.05$ \\
\hline $\mathrm{RR}$ & $\begin{array}{c}\text { Mean } \\
\text { S.D }\end{array}$ & $\begin{array}{l}21 \\
0.8\end{array}$ & $\begin{array}{c}26.3 \\
1.7\end{array}$ & 6.14 & $<0.01$ \\
\hline $\mathrm{HR}$ & $\begin{array}{c}\text { Mean } \\
\text { S.D }\end{array}$ & $\begin{array}{l}84 \\
2.6\end{array}$ & $\begin{array}{c}90.3 \\
4.9\end{array}$ & 10.00 & $<0.01$ \\
\hline Dyspnoea & $\begin{array}{c}\text { Mean } \\
\text { S.D }\end{array}$ & $\begin{array}{l}0.3 \\
0.5\end{array}$ & $\begin{array}{l}1.5 \\
1.0\end{array}$ & 2.60 & $<0.05$ \\
\hline Fatigue & $\begin{array}{c}\text { Mean } \\
\text { S.D }\end{array}$ & $\begin{array}{l}0.5 \\
0.6\end{array}$ & $\begin{array}{c}1 \\
0.8\end{array}$ & 1.00 & $>0.05$ \\
\hline SBP & $\begin{array}{c}\text { Mean } \\
\text { S.D }\end{array}$ & $\begin{array}{c}112.5 \\
5.0\end{array}$ & $\begin{array}{c}110 \\
0\end{array}$ & 1.00 & $>0.05$ \\
\hline DBP & $\begin{array}{c}\text { Mean } \\
\text { S.D }\end{array}$ & $\begin{array}{c}80 \\
14.1\end{array}$ & $\begin{array}{l}75 \\
5.8\end{array}$ & 1.00 & $>0.05$ \\
\hline $\begin{array}{l}\text { Distance } \\
\text { Covered }\end{array}$ & $\begin{array}{c}\text { Mean } \\
\text { S.D }\end{array}$ & $\begin{array}{c}232.5 \\
83.8\end{array}$ & & 5.55 & $<0.01$ \\
\hline & $\begin{array}{l}\text { sses } \\
(A 7)\end{array}$ & it of 7 & ime & $6 M$ & \\
\hline
\end{tabular}

SPO2-oxygen saturation, RR-respiratory rate, HR-heart rate, SBP-systolic blood pressure, DBP-diastolic blood pressure, SD-standard deviation

\begin{tabular}{|c|c|c|c|c|c|}
\hline \multicolumn{2}{|c|}{ Variable } & $\begin{array}{c}\text { Pre } \\
6 \\
\text { MWT }\end{array}$ & $\begin{array}{c}\text { Post } \\
6 \\
\text { MWT }\end{array}$ & $\begin{array}{c}\text { T } \\
\text { value }\end{array}$ & P value \\
\hline SPO2 & $\begin{array}{c}\text { Mean } \\
\text { S.D }\end{array}$ & $\begin{array}{c}96.7 \\
1.9\end{array}$ & $\begin{array}{c}94.3 \\
2.8\end{array}$ & 3.74 & $<0.01$ \\
\hline RR & $\begin{array}{c}\text { Mean } \\
\text { S.D }\end{array}$ & $\begin{array}{c}23 \\
2.3\end{array}$ & $\begin{array}{c}28.6 \\
3.6\end{array}$ & 7.41 & $<0.01$ \\
\hline HR & $\begin{array}{c}\text { Mean } \\
\text { S.D }\end{array}$ & $\begin{array}{c}91.7 \\
11.6\end{array}$ & $\begin{array}{c}97.6 \\
11.2\end{array}$ & 7.08 & $<0.01$ \\
\hline Dyspnoea & $\begin{array}{c}\text { Mean } \\
\text { S.D }\end{array}$ & $\begin{array}{c}1.0 \\
0\end{array}$ & $\begin{array}{c}2.1 \\
1.1\end{array}$ & 2.85 & $<0.05$ \\
\hline Fatigue & $\begin{array}{c}\text { Mean } \\
\text { S.D }\end{array}$ & $\begin{array}{c}0.7 \\
0.5\end{array}$ & $\begin{array}{c}0.9 \\
0.8\end{array}$ & 0.54 & $>0.05$ \\
\hline SBP & $\begin{array}{c}\text { Mean } \\
\text { S.D }\end{array}$ & $\begin{array}{c}118.6 \\
22.7\end{array}$ & $\begin{array}{c}118.6 \\
22.7\end{array}$ & 0.00 & - \\
\hline DBP & $\begin{array}{c}\text { Mean } \\
\text { S.D }\end{array}$ & $\begin{array}{c}82.9 \\
12.5\end{array}$ & $\begin{array}{c}75.7 \\
11.3\end{array}$ & 1.70 & $>0.05$ \\
\hline $\begin{array}{c}\text { Distance } \\
\text { Covered }\end{array}$ & $\begin{array}{c}\text { Mean } \\
\text { S.D }\end{array}$ & $\begin{array}{c}237.7 \\
57.3\end{array}$ & & 10.98 & $<0.01$ \\
\hline \multicolumn{7}{|c|}{ Fig. 5: Assessment of 7 Parameters of 6MWT } \\
(ATS) in Moderate COPD (N=7)
\end{tabular}

SPO2-oxygen saturation, RR-respiratory rate, HR-heart rate, SBP-systolic blood pressure, DBP-diastolic blood pressure, SD-standard deviation

\begin{tabular}{|c|c|c|c|c|c|}
\hline \multicolumn{2}{|c|}{ Variable } & $\begin{array}{l}\text { Pre-6 } \\
\text { MWT }\end{array}$ & $\begin{array}{c}\text { Post-6 } \\
\text { MWT }\end{array}$ & $\begin{array}{c}\text { T } \\
\text { value }\end{array}$ & $\begin{array}{c}P \\
\text { value }\end{array}$ \\
\hline SPO2 & $\begin{array}{c}\text { Mean } \\
\text { S.D }\end{array}$ & $\begin{array}{c}96.4 \\
1.7\end{array}$ & $\begin{array}{c}94.6 \\
3.5\end{array}$ & 2.78 & $<0.05$ \\
\hline RR & $\begin{array}{c}\text { Mean } \\
\text { S.D }\end{array}$ & $\begin{array}{c}22.5 \\
1.5\end{array}$ & $\begin{array}{c}28.7 \\
2.7\end{array}$ & 13.19 & $<0.01$ \\
\hline HR & Mean & 87.3 & 98.8 & 7.36 & $<0.01$ \\
\hline
\end{tabular}

\begin{tabular}{|c|c|c|c|c|c|}
\hline & S.D & 16.7 & 15.2 & & \\
\hline \multirow{2}{*}{ Dyspnoea } & Mean & 0.9 & 1.7 & \multirow{2}{*}{3.74} & \multirow{2}{*}{$<0.01$} \\
\hline & S.D & 0.4 & 0.8 & & \\
\hline \multirow{2}{*}{ Fatigue } & Mean & 0.9 & 1.3 & \multirow{2}{*}{1.89} & \multirow{2}{*}{$<0.05$} \\
\hline & S.D & 0.4 & 1.2 & & \\
\hline \multirow{2}{*}{ SBP } & Mean & 118.6 & 121.4 & \multirow{2}{*}{2.28} & \multirow{2}{*}{$<0.05$} \\
\hline & S.D & 1.9 & 8.6 & & \\
\hline \multirow{2}{*}{ DBP } & Mean & 80.7 & 80.7 & \multirow{2}{*}{0.00} & \multirow{2}{*}{$>0.05$} \\
\hline & S.D & 10.7 & 9.9 & & \\
\hline Distance & Mean & 186.7 & & \multirow{2}{*}{9.88} & \multirow{2}{*}{$<0.01$} \\
\hline Covered & S.D & 70.5 & & & \\
\hline \multicolumn{6}{|c|}{$\begin{array}{c}\text { Fig. 6: Assessment of } 7 \text { Parameters of 6MWT } \\
\text { (ATS) in Severe COPD }(n=14)\end{array}$} \\
\hline
\end{tabular}

SPO2-oxygen saturation, RR-respiratory rate, HR-heart rate, SBP-systolic blood pressure, DBP-diastolic blood pressure, SD-standard deviation

\section{DISCUSSION}

In this study, 7 parameters in $6 \mathrm{MWT}$ is used to correlate the severity of COPD. In this 25 subjects $-40 \%$ of them belonged to age group of $60-70$ years. In weight wise-44\% belonged to 50-60 kgs. Mild group consists of $16 \%$ and the parameters like Dyspnoea, Heart rate, Respiratory rate, Distance covered statistically significant. Moderate group of 28\% showed significant in the parameters like Dyspnoea, Heart rate, Respiratory rate, Distance covered in addition of oxygen saturation.

Maximum numbers were severe groups of patients with $56 \%$; the parameters showed statistically significant were Dyspnoea, Heart rate, Respiratory rate, Oxygen saturation, Systolic Blood Pressure and Distance covered.

Guyatt described a significant correlation between the results of a walking rest and a bicycle ergometer test in group of patients with chronic lung disease and heart failure.

Peeters et al found a significant correlation between the distance walked in the 6MWT and the distance walked in the treadmill test in a group of elderly patients with chronic heart failure. ${ }^{9}$

We believe the test correlations found for Dyspnoea, Heart rate, Respiratory rate and Distance covered in our study are remarkable. The fact that patients control their speed in the former and the duration of the latter may be on explanation.

This provides further support for the use of the 6MWT as a valid substitute determine the severity of COPD. Our study is not without limitations. A small sample size and a nonuniform distribution of the patients according to COPD GOLD severity are some among them.

\section{CONCLUSION}

The results from this study suggest that the 6MWT may be used as a valid substitute for PFT to determine exercise capacity in COPD patients. What makes the advantage of the 6MWT test to the older patients is that it involves a familiar activity, which can be adjusted at their own pace throughout the whole test. Furthermore, the test is a part of their daily activities unlike other physical activities like bicycling and treadmill walking.

The fact that the 6MWT needs no expensive apparatus, is easy to administer and does not expose the patients to any additional risk such as falling off the bicycle, ergometer or treadmill can make it more feasible for smaller rehabilitation 
centres to serve this patient group. It is a safe and welltolerated test. ${ }^{10-14}$

Hence, it is concluded that six minute walk test is a useful tool in assessing the severity of chronic obstructive pulmonary disease patients. The six minute walk test is relatively safe and well tolerated, is simple to administer.

\section{REFERENCES}

1. Mannino DM, Buist AS. Global burden of COPD: risk factors, prevalence, and future trends. Lancet 2007;370(9589):765-73.

2. Panos RJ, Eschenbacher W. Exertional desaturation in patients with chronic obstructive pulmonary disease. J Chron Obstr Pulm Dis 2009;6(6):478-87.

3. ATS committee on proficiency standards for clinical pulmonary function laboratories. ATS statement: guidelines for the six-minute walk test. Am J Respir Crit Care Med 2002;166:111-7.

4. Enright PL, McBurnie MA, Bittner V, et al. The 6-min walk test: a quick measure of functional status in elderly adults. Chest 2003;123(2):387-98.

5. Bauerle O, Chrusch CA, Younes M. Mechanisms by which COPD affects exercise tolerance. Am J Respir Crit Care Med 1998;157(1):57-68.

6. Iwama AM, Andrade GN, Shima P, et al. The six-minute walk test and body weight-walk distance product in healthy Brazilian subjects. Brazilian J Med Biol Res 2009;42(11):1080-5.
7. Takigawa N, Tada A, Soda R, et al. Distance and oxygen desaturation in 6-minute walk test predict prognosis in COPD patients. Respir Med 2007;101(3):561-7.

8. NHLBI/WHO workshop report. Global initiative for COPD: global strategy for the diagnosis, management and prevention of COPD. National institutes of health, 2006. Available at: http//www.gold.com.

9. Chetta A, Zanini A, Pisi G, et al. Reference values for the 6-min walk test in healthy subjects 20-50 years old. Respir Med 2006;100(9):1573-8.

10. Alfred P Fishman. Textbook of pulmonary disease and disorders. Third edition romain a pauwels at 2001.

11. Butland Rja, Pangt, Gross Er Woodcock AA, et al. Two-6 and 12 minute walking test in respiratory test in respiratory disease. Bmj 1982;284(6329):1607-68.

12. Lipkin DP, Scrivin AJ, Crake T, et al. Six minute walking test for assessing exercise capacity in chronic heart failure. Bmj 1986;292(6521):653-5.

13. Troosters T, Grosselink R, Decramer M. Six minute walking distance in healthy elderly subjects. Eur Respir J 1999;14(2):270-4.

14. Enright PL, McBurnie MA, Bittner V, et al. The six minute walk test: a quick measure of functional status in elderly adults. Chest 2003;123(2):387-98. 